\title{
Comparison between DNA Image Analysis and Cytology in the Assessment of Spermatogenesis
}

\author{
A. Al-Salim a I. Francis ${ }^{\text {c }}$ A. Al-Juwaiser ${ }^{b} \quad$ M. Abdulla ${ }^{\text {b }} \quad$ B. John ${ }^{c}$ \\ Departments of asurgery, Andrology, and bPathology, Mubarak Hospital, Ministry of Health, \\ and ${ }^{c}$ Department of Pathology, Faculty of Medicine, Kuwait University, Kuwait
}

\section{Key Words}

Testis · Azoospermia · Fine-needle aspiration cytology $\cdot$ DNA analysis

\begin{abstract}
Objective: The aim of the study is to evaluate the DNA image analysis of smears in assessing spermatogenesis and to compare it to routine fine-needle aspiration cytology (FNAC). Methods: A total of 33 testicular needle aspirates from azoospermic infertile patients were blindly studied by 2 different cytologists separately; one studied the FNAC and the other evaluated the DNA contents. DNA image analysis was done on Feulgenstained cytology smears. The generated DNA histogram was compared to cytology results. Results: Twenty-three (69.7\%) testes showed complete agreement between the image analysis and cytology mainly in the presence of sperms, while $10(30.3 \%)$ testes showed discrepancy between the DNA image analysis and cytology, mainly in the syndrome with Sertoli cells only and sper-
\end{abstract}

\begin{tabular}{ll}
\hline KARGER & (1) 1999 S. Karger AG, Basel \\
Fax +41 61 306 1234 34 & \\
$\begin{array}{l}\text { E-Mail karger@karger.ch } \\
\text { www.karger.com }\end{array}$ & $\begin{array}{l}\text { Accessible online at: } \\
\text { www.karger.com/journals/mpp }\end{array}$
\end{tabular}

matogenic arrest. Conclusions: DNA image analysis of testicular aspirates is an objective and reliable method in assessing spermatogenesis, while cytology is a relatively subjective method and observer dependent. The discrepancy may be explained by cytologist inter- and intra-observer variability in evaluating spermatogenesis in the FNAC specimens.

Copyright $\odot 1999$ S. Karger AG, Basel

\section{Introduction}

Male infertility accounts for more than $50 \%$ of the causes of infertile couples. Testicular biopsy has long been the standard method to assess spermatogenesis which is an invasive procedure and carries anaesthetic risk. Fineneedle aspiration cytology (FNAC) is less invasive, less traumatic and relatively subjective and observer dependent. In the era of advanced technology for the treatment of male infertility, the need for few sperms to be used for micro-injection of the partner eggs

Dr. A. Al-Salim
PO Box 9704
Ahmadi 61008 (Kuwait)
Tel. +965 5312700, ext. 3420, Fax +965 5334439
E-Mail aalsalim@hotmail.com

Dr. A. Al-Salim

Ahmadi 61008 (Kuwait)

E-Mail aalsalim@hotmail.com 
Table 1. DNA histogram patterns of testicular FNAC smears

\begin{tabular}{lll}
\hline Pattern & Cell content & Comment \\
\hline 1A & $\begin{array}{l}\text { mainly haploid 1c and tetraploid 4c with fewer } \\
\text { diploid 2c cells }\end{array}$ & normal spermatogenesis \\
1B & $\begin{array}{l}\text { mainly diploid cells with fewer haploid and } \\
\text { tetraploid cells }\end{array}$ & hypospermatogenesis \\
2 & diploid 2c and tetraploid 4c cells only & spermatogenic arrest \\
3 & diploid cells $2 \mathrm{c}$ & Sertoli-cell-only syndrome \\
\hline
\end{tabular}

makes it necessary to have new methods that are reliable and objective, to evaluate testicular tissue. The aim of the study is to investigate the reliability of DNA image analysis in the assessment of spermatogenesis as an objective method when compared to FNAC.

\section{Material and Method}

Thirty-three FNAC samples obtained from the testes of patients who attended the Infertility Clinic were included in this study. The procedure was carried out regardless of the size of the testis or the hormonal profile. The aspirates were subjected to cytological examination and DNA image analysis by two different cytologists; one examined and evaluated the FNAC and the other studied the DNA counterpart.

\section{FNAC Technique}

Under complete aseptic conditions, local anaesthesia ( $2 \%$ xylocaine) was injected into the spermatic cord at the scrotal neck, then the testes were punctured by a 23 -gauge needle connected to a $10-\mathrm{ml}$ syringe in the syringe holder (Cameco Syringe Pistol-Precision, Dynamics Corporation, San Fernando, Calif., USA).

Each testis was punctured at the mid-portion opposite the epididymis, then the needle was moved in different directions while under suction pressure to widen the sample area. The aspirate was then spread on glass slides; some slides were wet, fixed in $95 \%$ ethyl alcohol for Papanicolaou staining, while the remaining slides were allowed to dry for May-Grünwald-Giemsa staining. Two cytologists (M.A. and A.J.) studied the smears for spermatogenesis and adequacy.

\section{DNA Image Analysis}

One May-Grünwald-Giemsa-stained representative smear from each case was coded by the cytologist and submitted for blind DNA image analysis. The smears were destained for $2 \mathrm{~h}$ in acid-alcohol solution, fixed in $10 \%$ neutral buffered formalin and submitted to Feulgen staining [1].

Smears of isolated normal human lymphocytes fixed in formalin were stained together with the testicular smears and used as reference diploid cell population. A pathologist (I.F.) unaware of the original cytology results analysed Feulgen-stained smears for the DNA distribution pattern.

This was carried out on the cell analysis system [2], using the cytology smear option of ploidy software. The machine was first calibrated using the cytology smears of known diploid cells (normal human lymphocytes). The quality of Feulgen staining was regarded as acceptable when the density co-efficient of variation was less than or equal to 5 in the diploid cells in each staining batch. In order to enable the image analysis to detect spermatozoa, a special filter was constructed for a haploid population using size and shape values obtained from smears of normal spermatozoa obtained previously. In each case a total of 200 cells inclusive of spermatozoa was measured. DNA histograms of each case were plotted and printed for reference. Each histogram was assigned a numeric value of 1-3 as shown in table 1 .

\section{Results}

Thirty-three testicular FNA smears were studied cytologically and by image analysis. The results were divided into 3 groups accord- 
Fig. 1. a DNA histogram of testis aspirate demonstrating 3 peaks consistent with normal spermatogenesis. b FNAC of testis with normal spermatogenesis. Giemsa stain. $\times 40$.
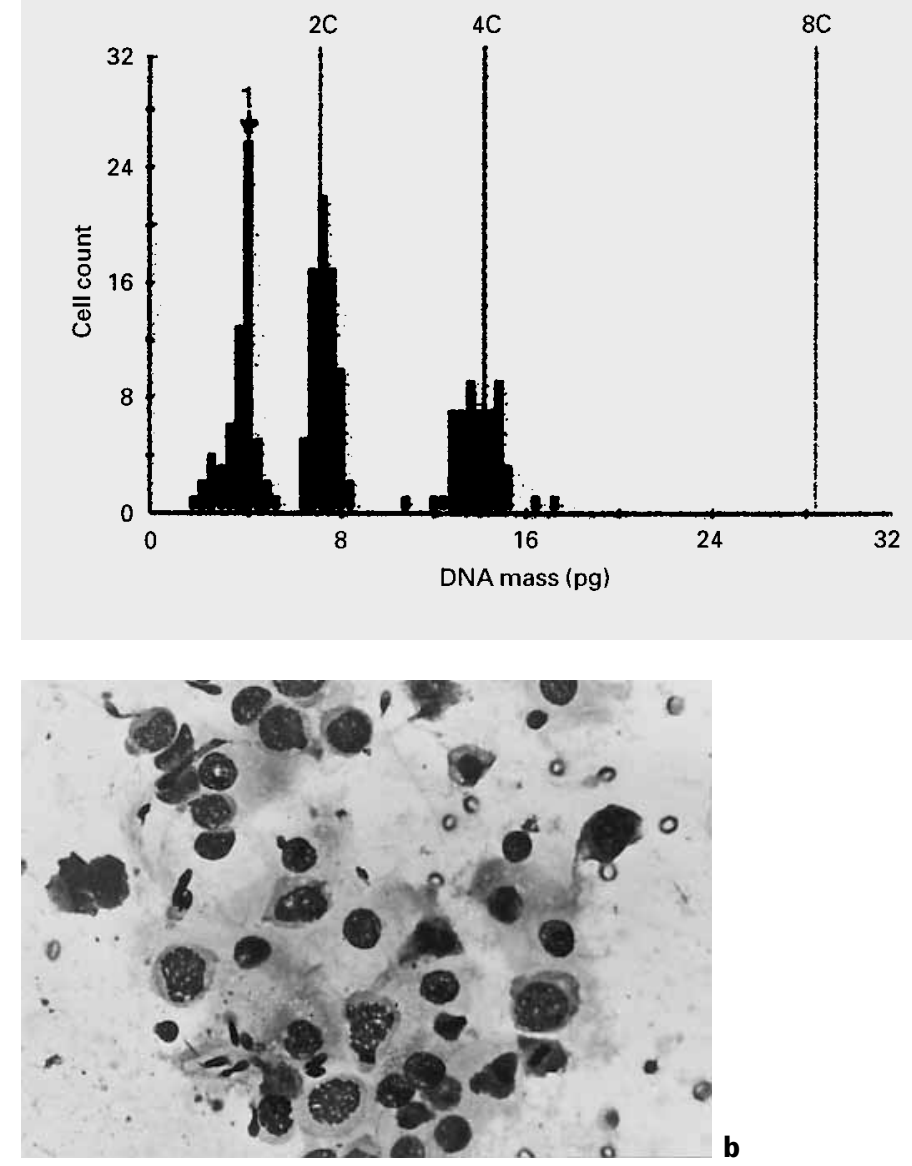

ing to the distribution and density of DNA content, full spermatogenesis, spermatogenic arrest or Sertoli cell group only.

\section{Group 1}

This group includes 16 testes with normal spermatogenesis or hypospermatogenesis (pattern $1 \mathrm{~A}$ and $1 \mathrm{~B}$, table 1). In this group the histogram showed 3 peaks, haploid 1c, diploid $2 \mathrm{c}$ and tetraploid $4 \mathrm{c}$. There was a total agreement between the DNA image analysis (fig. 1a) and cytology (fig. 1b).

Image Analysis in Spermatogenesis

\section{Group 2}

There were 7 testes with spermatogenic arrest in this group (pattern 2 in table 1). In this group the histogram showed 2 peaks, one representing the Sertoli cells $2 \mathrm{c}$ and the other representing the spermatocytes $4 c$ (fig. 2a). Only 2 cases showed an agreement between DNA image analysis and cytology (fig. 2b), while 5 cases showed disagreement between the cytology and DNA results. In these 5 cases, the cytology showed areas of focal or mild hypospermatogenic activities with few sperms and/or spermatids.

Med Principles Pract 1999;8:309-314 
Fig. 2. a DNA histogram of testis aspirate demonstrating 2 peaks, consistent with spermatogenic arrest. b FNAC of testis with spermatogenic arrest at the primary spermatocyte level. Giemsa stain. $\times 20$.
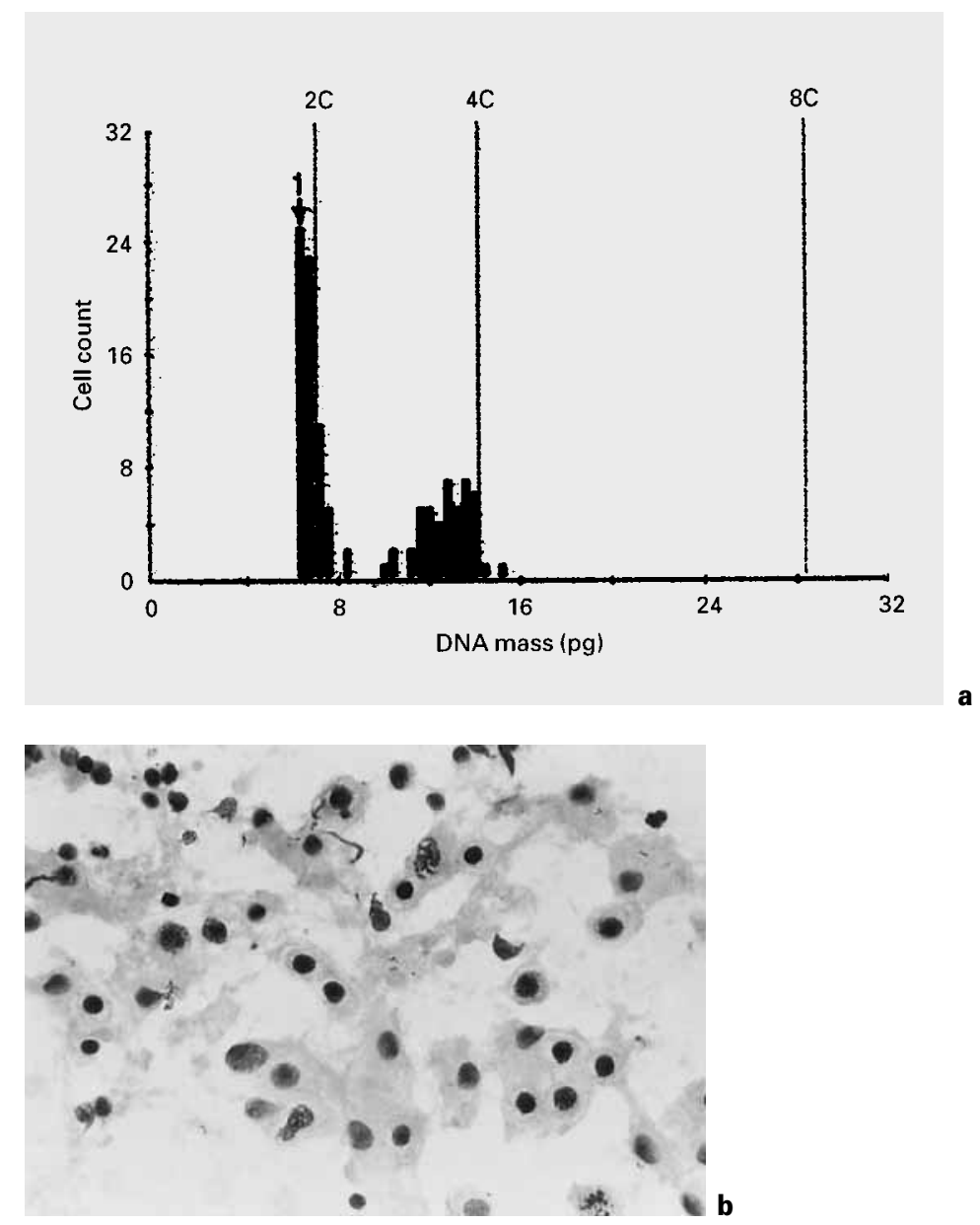

\section{Group 3}

There were 10 testes with Sertoli cells only (pattern 3 in table 1) in this group, and the histogram showed 1 peak representing the Sertoli cells 2c (fig. 3a). Five testes showed a total agreement between the DNA image analysis and cytology (fig. 3b), whereas another 5 showed foci of spermatogenesis, 3 of which were with arrest.

Of the total number of 23 testes, $69.7 \%$ showed an agreement between the DNA image analysis and the cytology results, while only $30.3 \%$ (10) showed a disagreement.

\section{Discussion}

Testicular biopsy is the standard test for the evaluation of the presence of spermatogenesis; however, it is an invasive procedure and needs anaesthesia. There is strong evidence that FNAC of the testis is an accurate and simple method when compared to open testicular biopsy in the evaluation of spermatogenesis [3]. However, it is a subjective method and observer dependent. DNA flow cytometry has been used by some investigators for the assessment of spermatogenesis [4, 
Fig. 3. a DNA histogram of testis aspirates demonstrating 1 peak, consistent with total atrophy (Sertoli-cells-only syndrome). b FNAC of testis with complete atrophy; Sertoli cells only are seen. Giemsa stain. $\times 40$.
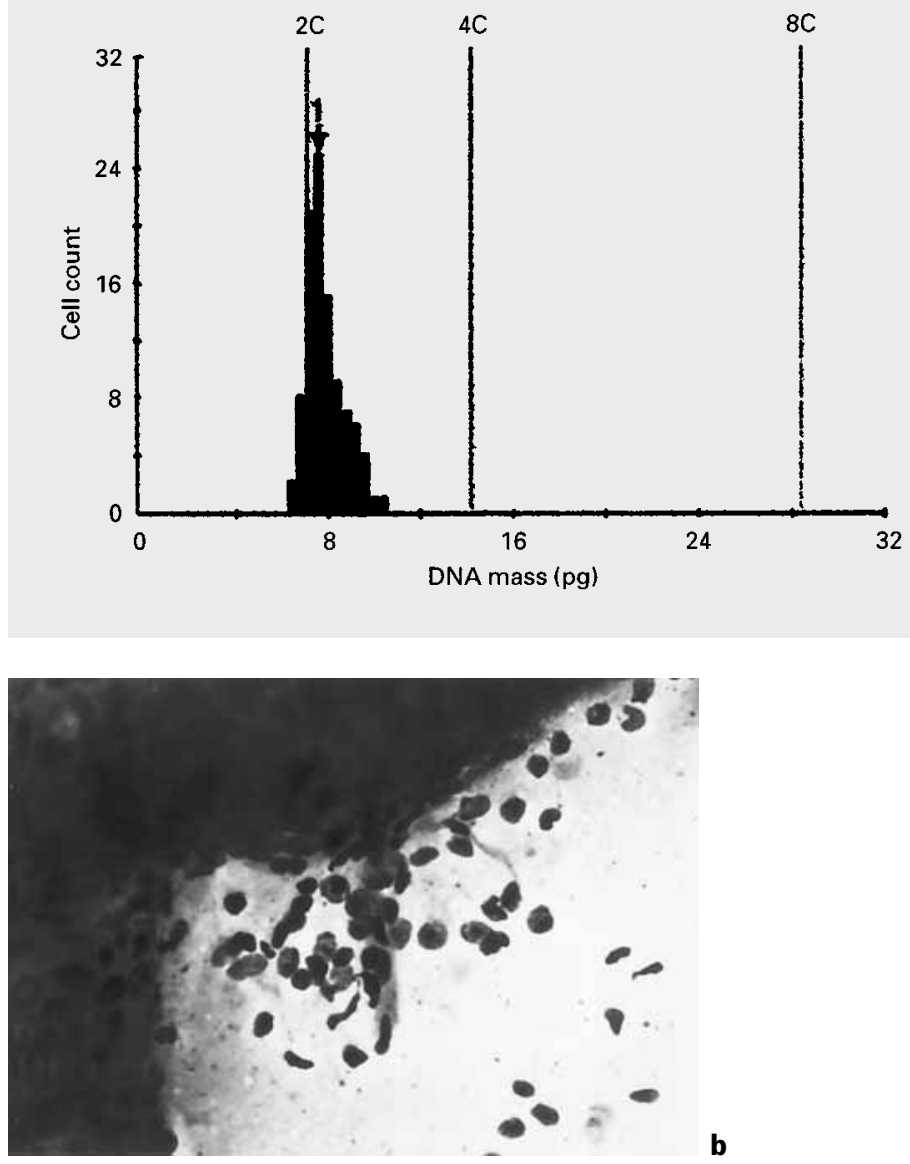

5] and has proved to be a reliable method in the differentiation of haploid $1 \mathrm{c}$, diploid $2 \mathrm{c}$ and tetraploid $4 \mathrm{c}$ cell populations. This kind of investigation needs a specially designed and equipped laboratory and skilled technician [6].

DNA image analysis for cytology cases is a simple technique and requires only formalinfixed air-dried smears, prepared from FNAC of the testis. It can evaluate the cell components of the testis on the basis of their DNA content $[6,7]$, where the Sertoli cells are diploid (2c), spermatozoa and spermatids are haploid (1c) and spermatocytes are tetraploid (4c). Normal spermatogenesis gives a histogram with 3 peaks: the first representing the Sertoli cells, the second spermatocytes and the third the spermatozoa. This technique has the added advantage of the possibility of repeating the measurement of the same case as well as re-assessing FNAC smears after slide destaining. This allows proper comparison to conventional cytological evaluation. However, the use of flow cytometry to analyse a relatively large number of cell elements when compared to image analysis has been shown 
to provide a more representative DNA histogram. Technological advances in the treatment of male infertility give hope that many infertile couples can have a child of their own, with fertilization rates more than $90 \%$ per attempt and clinical pregnancy in excess of $25 \%$ regardless of sperm shape or the level of follicle-stimulating hormone [8, 9]. The method of using microinjection of a single sperm inside the cytoplasm of the ovum, intracytoplasm sperm injection, is an expensive method of treatment, and the availability of sperms or spermatids by testicular sperm aspiration during the time of egg collection is vital for completion of the procedure.

Our study has clearly demonstrated that both conventional cytology and static DNA image analysis are equally valuable in detecting the presence of sperms or spermatids. In abnormal cases like spermatogenic arrest or Sertoli-cells-only syndrome, we found some discrepancy between the above methods. This could be attributed in part to the limited amount of cellular material available to DNA analysis. In groups 2 and 3, the discrepancies between cytology and DNA histograms are most probably due to the relatively small number of cells selected for DNA analysis. It is obvious from such observations that cytological evaluation and DNA analysis are complementary to each other. Cytology has proven to be an adequate procedure to report the presence of sperms, particularly in cases of obstructive aetiology.

To increase the accuracy of DNA analysis it is suggested that the studied cell number should be increased. It has also been suggested that variability between different DNA analysis sessions could affect the results [8].

\section{Conclusion}

DNA image analysis can assess and quantify the level of spermatogenesis. It is a practical and convenient method and provides the clinician with enough information to decide the appropriate management of male infertility. The disadvantage of this kind of investigation is that it cannot provide the morphological or structural changes as well as the quantitative evaluation of the testicular activity.

\section{References}

1 Bradbury P, Rae K: Connective tissues and stains; in Bancroft JD (ed): Theory and Practice of Histological Techniques. Edinburgh, Churchill Livingstone, 1996, vol 7, pp 136137.

2 Cas 200 system, cell analysis systems. User manual, catalogue No 201025-00.

3 Kessaris DN, Wasserman P, Mellinger BC: Histopathological and cytopathological correlations of percutaneous testis biopsy and open testis biopsy in infertile men. J Urol 1995; 153:1151-1155.
4 Kaufman DG, Nagler HN: Aspiration flow cytometry of the testes in the evaluation of spermatogenesis in the infertile male. Fertil Steril 1987; 48:287-291.

5 Lee SE, Choo MS: Flow-cytometric analysis of the testes in infertile men: A comparison of the ploidy to routine histopathologic study. Eur Urol 1991;20:33-38.

6 Gottschalk-Sabag S, Weiss DB, Sherman Y: Assessment of spermatogenic process by deoxyribonucleic acid image analysis. Fertil Steril 1995;64:403-407.
7 Kim ED, Lin WW, Abrams J, Lipshultz LI: Testis biopsy image analysis effectively quantifies spermatogenic cell types. J Urol 1997;157: 147-150.

8 Fishel SB, Thornton S: The use of assisted reproduction technology (ART) for achieving conception in male infertility. Br J Urol 1995;75: 50-56.

9 Palermo GD, Cohen J, Alikani M, Adler A, Rosenwaks Z: Intracytoplasmic sperm injection: A novel treatment for all forms of male factor infertility. Fertil Steril 1995;63: 1231-1240. 